\title{
Dorsal Nasal Turbinate
}

National Cancer Institute

\section{Source}

National Cancer Institute. Dorsal Nasal Turbinate. NCI Thesaurus. Code C139163.

The nasal turbinate originating from the ethmoidal crest on the inner wall of the nasal bone and extending to the maxilla. 